Article

\title{
Okadaic Acid Toxin at Sublethal Dose Produced Cell Proliferation in Gastric and Colon Epithelial Cell Lines
}

\section{Miguel del Campo ${ }^{1}$, Héctor Toledo ${ }^{2}$ and Néstor Lagos ${ }^{1, *}$}

1 Laboratory of Membrane Biochemistry, Program of Physiology and Biophysics, Faculty of Medicine, University of Chile, Independencia 1027, Correo 7, Santiago 8380000, Chile; E-Mail: Miguel.delcampo@fucited.cl

2 Laboratory of Molecular Microbiology, Program of Cellular and Molecular Biology, Faculty of Medicine, University of Chile, Independencia 1027, Correo 7, Santiago 8380000, Chile; E-Mail: htoledo@med.uchile.cl

* Author to whom correspondence should be addressed; E-Mail: nlagos@med.uchile.cl; Tel./Fax: +56-02-2978-6309.

Received: 31 August 2013; in revised form: 29 October 2013 / Accepted: 12 November 2013 / Published: 2 December 2013

\begin{abstract}
The aim of this study was to analyze the effect of Okadaic Acid (OA) on the proliferation of gastric and colon epithelial cells, the main target tissues of the toxin. We hypothesized that $\mathrm{OA}$, at sublethal doses, activates multiple signaling pathways, such as Erk and Akt, through the inhibition of PP2A. To demonstrate this, we carried out curves of doses and time response against OA in AGS, MKN-45 and Caco 2 cell lines, and found an increase in the cell proliferation at sublethal doses, at $24 \mathrm{~h}$ or $48 \mathrm{~h}$ exposure. Indeed, cells can withstand high concentrations of the toxin at $4 \mathrm{~h}$ exposure, the time chosen considering the maximum time before total gastric emptying. We have proved that this increased proliferation is due to an overexpression of Cyclin B, a cyclin that promotes the passage from G2 to mitosis. In addition, we have demonstrated that OA induces activation of Akt and Erk in the three cells lines, showing that OA can activate pathways involved in oncogenesis. In conclusion, this study contributes to the knowledge about the possible effects of chronic OA consumption.
\end{abstract}

Keywords: okadaic acid; gastric cancer; colon cancer; PP2A; proliferation 


\section{Introduction}

Okadaic acid (OA) is the principal component of diarrhetic shellfish poisoning (DSP) toxins [1]. The symptomatology of DSP is developed within $30 \mathrm{~min}$ to $6 \mathrm{~h}$ after contaminated bivalve consumption and includes diarrhea (60\%), nausea (46\%), vomiting (31\%), and abdominal pain (77\%). In addition, it generates loss of epithelial integrity, erosion and hypersecretion in the intestines and increases the paracellular permeability. If the level of intoxication is mild, the syndrome evolves favorably toward total recovery in two to three days [2,3]. While there are no records of death, these toxins have been widely described as tumor promoters [4]. In fact, it has been speculated that consumption of seafood in areas where red tide is endemic increases the risk of gastro-intestinal cancer [5]. Currently, European standard maximum levels for total DSP toxins, cannot exceed $160 \mu \mathrm{g}$ OA equivalent $/ \mathrm{kg}$ shellfish meat [1]. Therefore, it is permitted to consume DST in chronically at low concentrations.

OA is a potent inhibitor against Ser/Thr Protein Phosphatase 2A (PP2A) and Protein Phosphatase 1 (PP1), with an IC50 of $0.1-1 \mathrm{ng} / \mathrm{mL}$ for PP2A and 100-fold higher IC50 for PP1 [6]. The PP2A plays a key role in the regulation of major cell metabolic pathways, such as translation, transcription and control of transition from $\mathrm{G} 2$ to the M phase of the cell cycle; it is a tumor suppressor protein and a positive regulator of apoptosis [7]. Through the inhibition of PP2A, OA generates cellular hyperphosphorylation, which can activate multiple signaling pathways, including the expression and secretion of inflammatory agents that can act as endogenous tumor promoters such as TNF- $\alpha$ [8]. Experimentally, it has been demonstrated that repeated exposure of OA induces tumor formation in mouse skin, glandular stomach and rat liver [4]. While OA has been reported to increase cell proliferation $[9,10]$, it is unknown whether it has the same effect on the gastric epithelium, the main target following oral administration of the toxin after acute doses [11-13]. Indeed, this effect is contradictory to its broad description as toxic agent, able to arrest the mitotic cycle, form DNA adducts and activate Caspases 3, 8 and 9, in many cell lines [14-17].

We hypothesize that the dual effect of OA is dose and time exposure dependent and that it activates cell proliferation signaling at sublethal doses. For this, the effect of OA on the viability of two models of gastric epithelium (AGS and MKN-45) and colon epithelium (Caco 2) was analyzed, studying the expression of Cyclin B1, a cyclin that promotes the passage from $\mathrm{G} 2$ to mitosis [18], and the activation of Akt and Erk, two canonical pathways of cell survival and proliferation, that are regulated by PP2A [19,20]. It is postulated that OA, in sublethal doses, can promote cellular proliferation and activate oncogenic pathways.

\section{Results and Discussion}

\subsection{OA Generate Cellular Proliferation at Sublethal Doses in Gastric and Colon Epithelium}

The effect of OA on cell proliferation was analyzed in AGS, MNK-45 and Caco 2 cell lines, for $24 \mathrm{~h}$ or $48 \mathrm{~h}$. For this, two different methodologies were used: 3-(4,5-dimethylthiazol-2-yl)-2, 5-diphenyltetrazolium bromide (MTT) assay and AlamarBlue Cell Viability Assay. No substantial differences were observed between AlamarBlue (Figure 1A,C,E) and MTT assay (data not shown). To display easier cell proliferation to sublethal concentrations, a bar chart with the significant differences 
is shown (Figure 1B,D,F). To see this effect during longer periods, we used Tripan blue exclusion for seven days (Figure 1G,H,I). Sublethal concentrations showed an increase in the cell proliferation, which in some cases was significant. At concentrations equal to or greater than $10 \mathrm{nM}$, at longer durations, cells tended to decrease or equate with the control. It was difficult to observe significant differences in this experiment due to the high proliferative rate of these cell lines or to the method limitations. Interestingly, gastric epithelial cells had a similar behavior, but not Caco 2, which showed increased resistance to toxicity of OA, compared with AGS and MKN-45, proving that the cytotoxicity and genotoxicity of OA are cell-line dependent [21].

Figure 1. Effect of Okadaic Acid (OA) treatment on cell proliferation. AGS (A), MKN-45 (B) and Caco 2 (C) were incubated for $24 \mathrm{~h}$ or $48 \mathrm{~h}$ with different concentrations of OA, and the proliferation was measured by AlamarBlue cell viability assay. In B, D-F, the chart bars show significant differences compared to the control $(N=12)$. G-I show the effect of treatment with OA for 7 days, in AGS, MKN-45 and Caco 2, respectively, using the Trypan blue method exclusion $(N=8)$. ${ }^{*} p<0.05 ; * * p<0.01 ; * * *<0.005$.

A

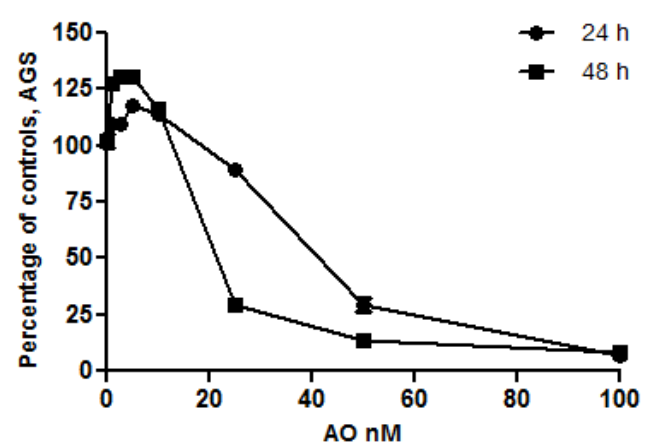

$\mathrm{C}$

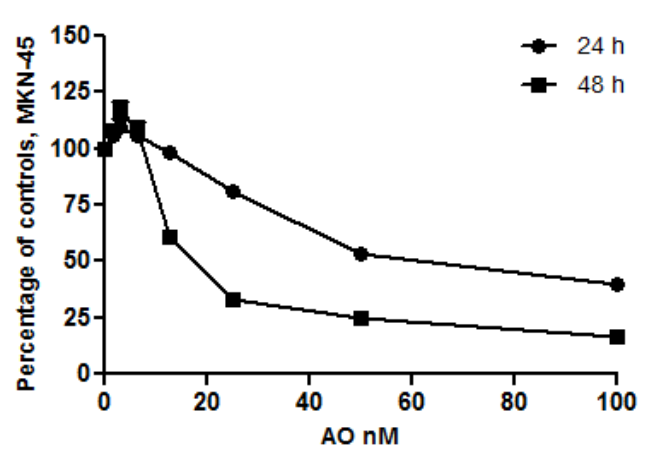

$\mathrm{E}$

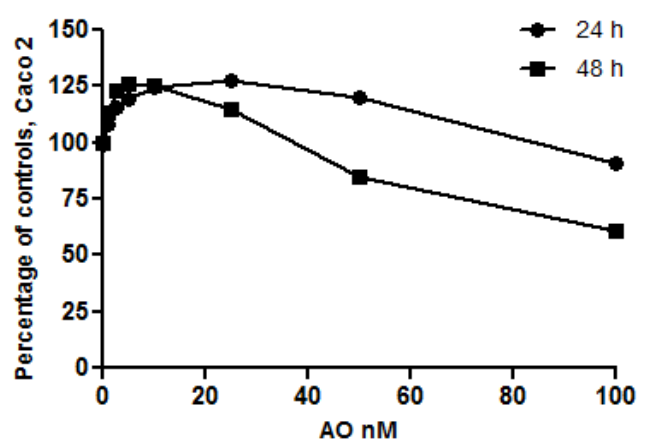

B

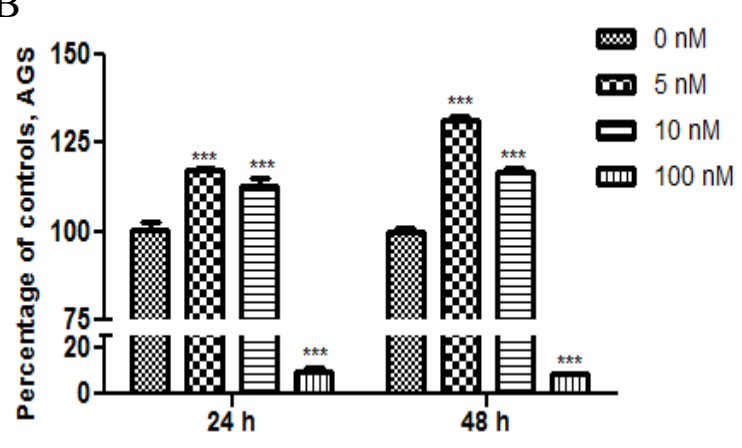

$\mathrm{D}$

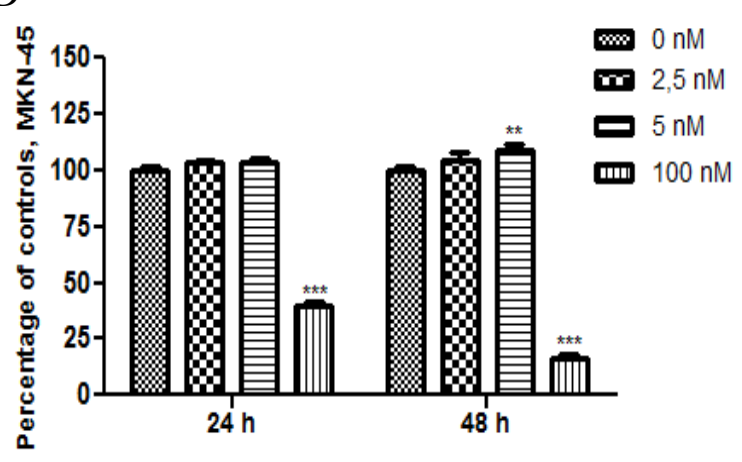

$\mathrm{F}$

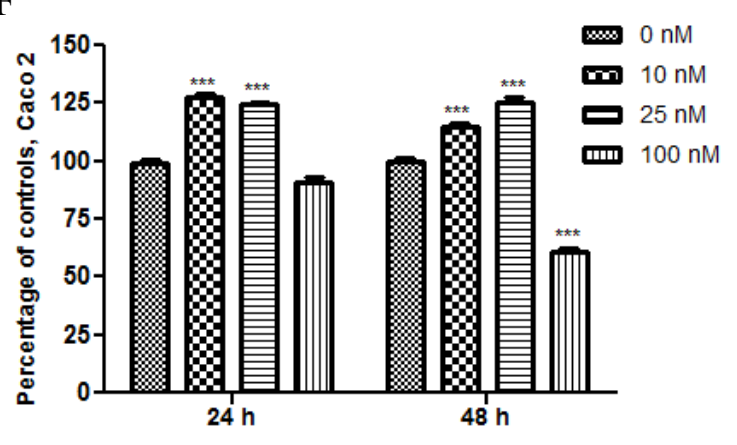


Figure 1. Cont.

G

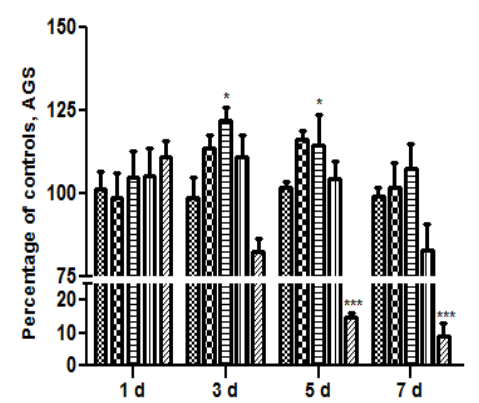

$\mathrm{H}$

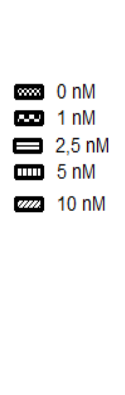

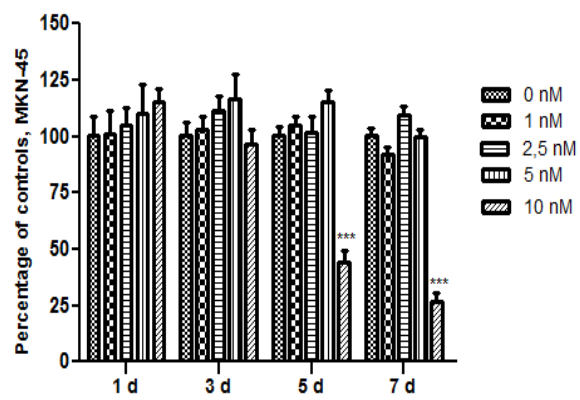

I

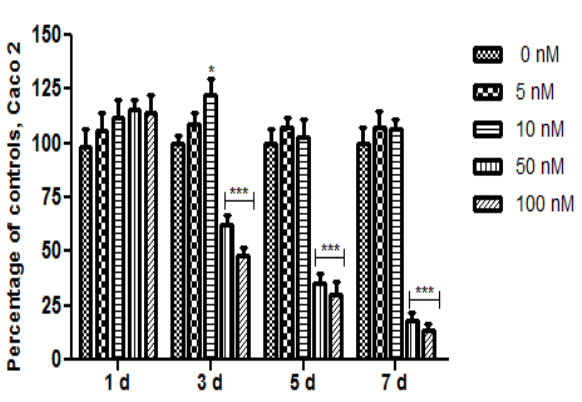

In order to see the effects of OA on cell proliferation in a more close physiological condition, the cells were exposed for $4 \mathrm{~h}$ to the toxin, a point in time at which the stomach presents a complete emptying of the food meal [22], and was analyzed at $48 \mathrm{~h}$. As the with previous results, the cultures showed an increase in cell proliferation at sublethal concentrations, with Caco 2 being more resistant to the toxicity of OA. In fact, the cultures can withstand higher concentrations and remain viable compared with no pulse experiment (Figure 2). These results demonstrate that gastric and colon epithelia can be exposed to lethal levels of OA for short periods of time without activating cellular death, increasing the risk of acting as a tumor promoter.

Figure 2. Effect of OA treatment for $4 \mathrm{~h}$ on cell viability. The viability was analyzed using the Alamarblue method. The three cell lines show increased resistance to the toxicity of OA with Caco 2 being the most resistant. In $\mathbf{B}$, the chart bar shows the significant differences compared to the control $(N=12)$. ${ }^{*} p<0.05 ; * * p<0.01 ; * * * p<0.005$.

A

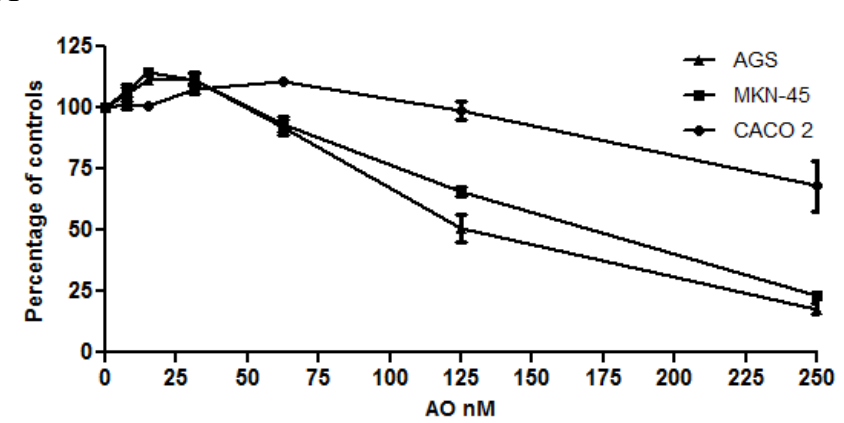

B

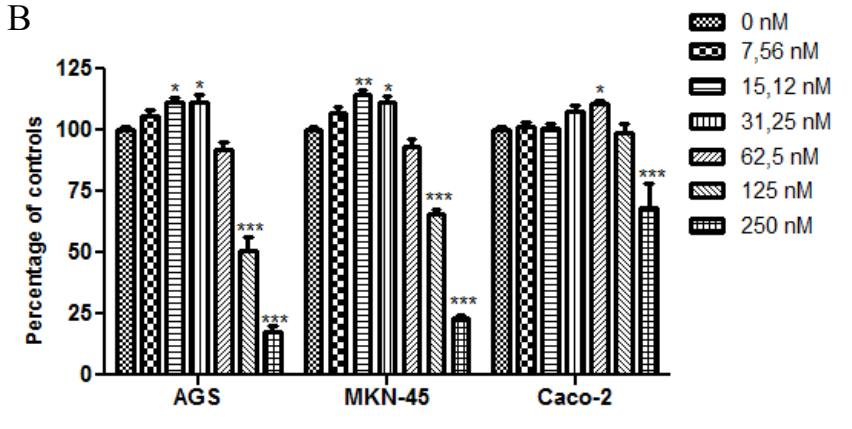

\subsection{Overexpression of Cyclin B as an OA Effect}

To prove that OA can increase the cell mitotic rate at sublethal concentrations, the expression of Cyclin B was analyzed. After treatment for $4 \mathrm{~h}$ or $24 \mathrm{~h}$ with OA at different concentrations, Cyclin B increased its expression in the three cells lines, with a dose response effect, even at concentrations in which culture viability was lower (Figure 3 ). This latter result is interesting since the cells have the input signal to the mitotic cycle; however, deregulation produced by OA could activate apoptosis or other forms of cell death. For the three cell lines, the increase in expression was greater at $4 \mathrm{~h}$ than at $24 \mathrm{~h}$, the time at which the cells tend to normalize in respect to the control. The expression of Cyclin B 
is regulated for multiple pathways, most of them deactivated by PP2A [18]. Therefore, OA would intensify inductive signals of Cyclin B, through inhibition of PP2A.

Figure 3. Treatment with OA generates overexpression of Cyclin B. By western blot, an increased expression of Cyclin B after exposure to OA for $4 \mathrm{~h}$ or $24 \mathrm{~h}$ is shown in all three cell lines. $(N=4$ for AGS and MKN-45; $N=3$ for Caco 2$) .{ }^{*} p<0.05,{ }^{* *} p<0.01$, $* * * p<0.005$.

\section{AGS}

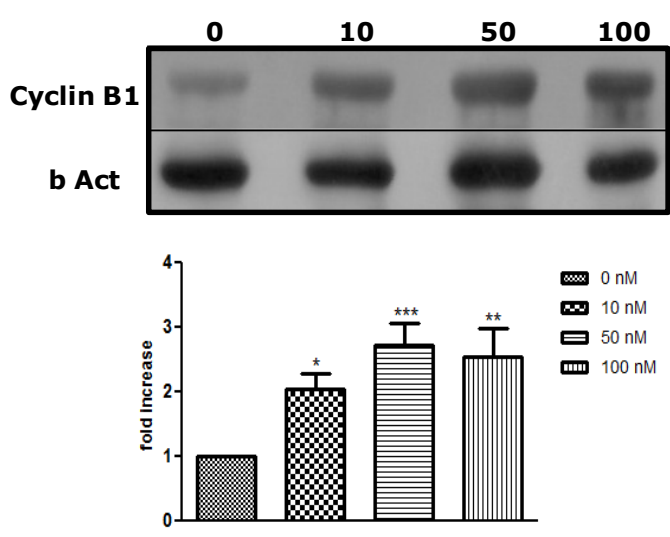

nM AO, 4 h

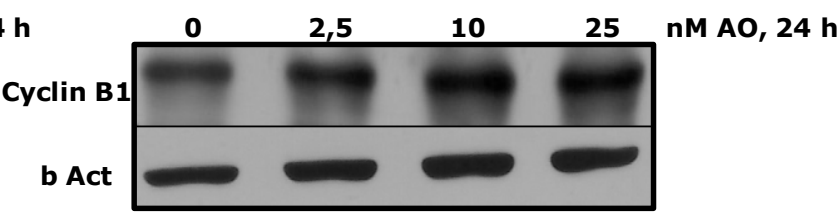

\section{MKN-45}

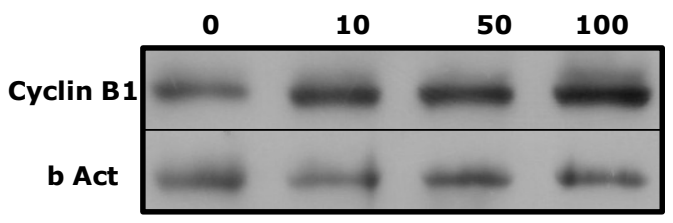

nM AO, 4 h
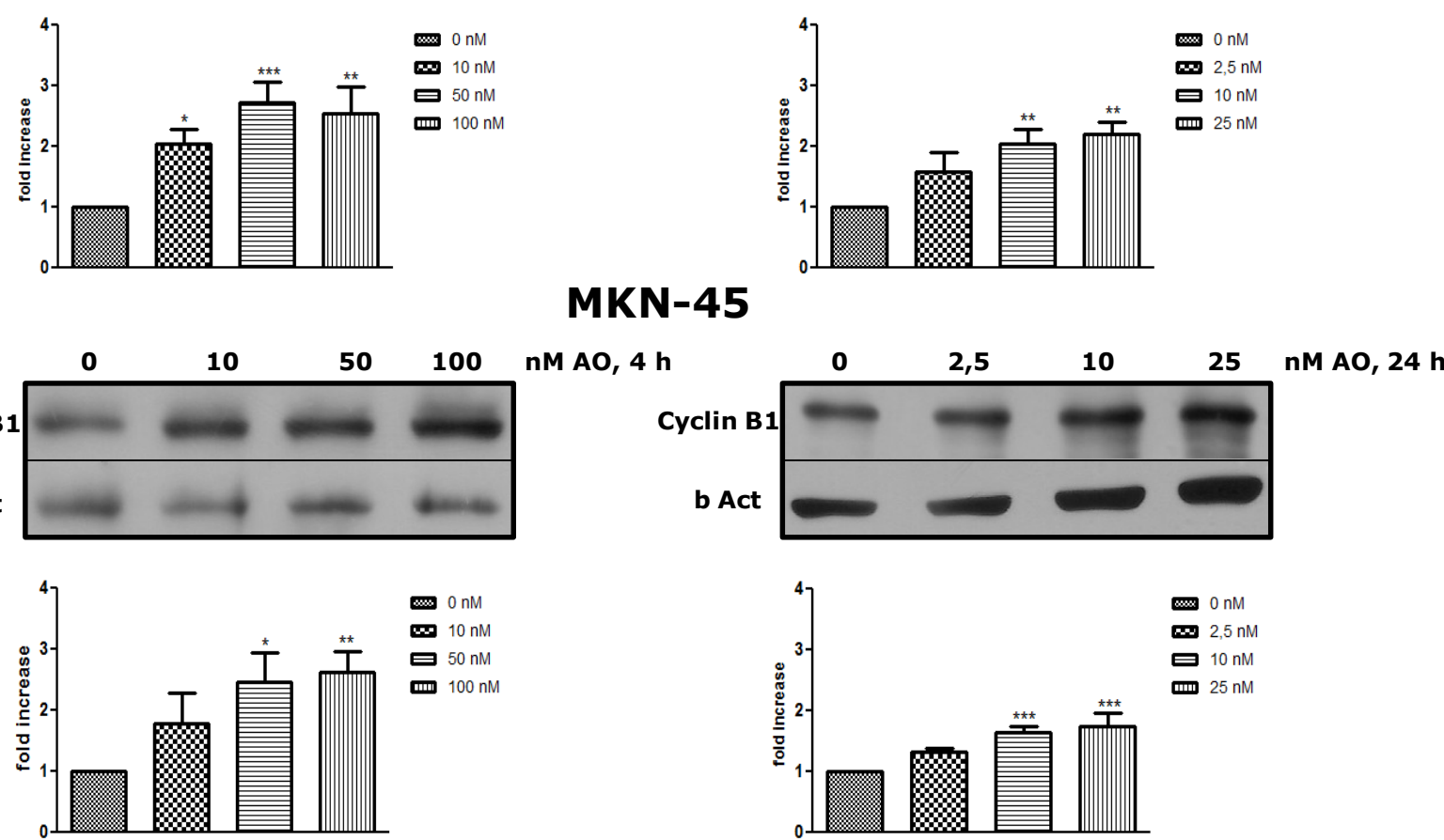

Caco 2
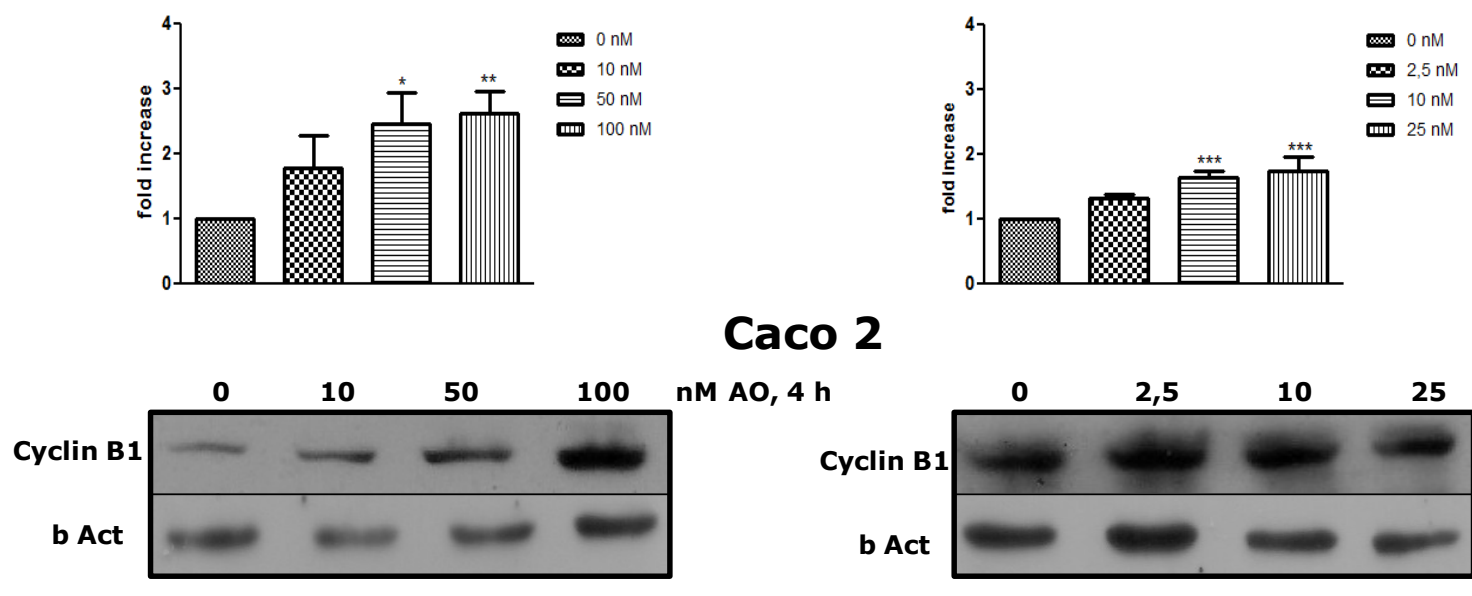

MO, 4 h
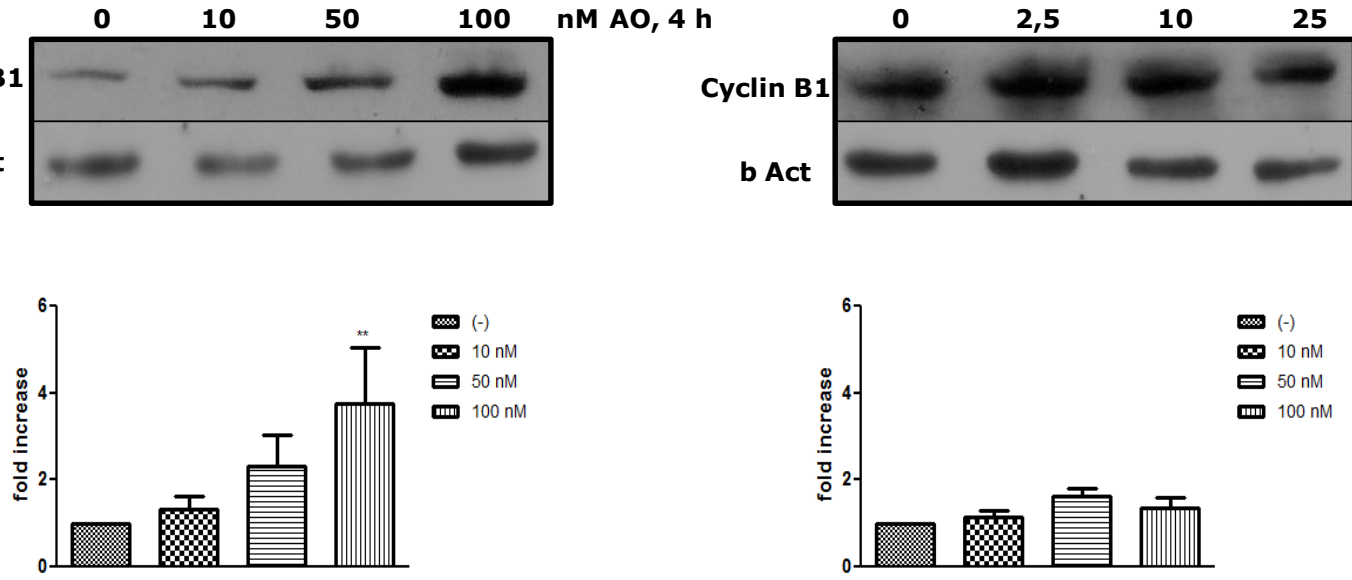


\subsection{Activation of Akt and Erk Pathways as an OA Effect}

Next, we wanted to see whether OA could activate canonical pathways of proliferation such as Akt and Erk. Akt is the major downstream effector in the PI3-kinase pathway and requires the phosphorylation of Thr308 and Ser473 to be fully active [19]. Erk is central to signaling by growth factors. Their activation involves a cascade of phosphorylation events initiated by stimulation of Ras and ending by MAPK kinases (MEK1/2)-mediated dual phosphorylation of Erk1/2 at Thr and Tyr residues [20]. Both Akt and Erk are essential regulators of cell survival, proliferation, and metabolism and are substrates of PP2A, who acts as deactivator of them. After treatment with OA for $4 \mathrm{~h}$, the three cell lines showed that the phosphorylated forms of Akt and Erk were increased, being significant in some cases (Figure 4).

Figure 4. Treatment with OA generates activation of Akt and Erk pathways. By WB, an increased of p308-Akt1, p-473-Akt1 and p-Erk1/2 is shown relative to basal levels of Akt and Erk as an effect of OA after $4 \mathrm{~h}(N=3) .{ }^{*} p<0.05, * * p<0.01, * * * p<0.005$.

\section{AGS}

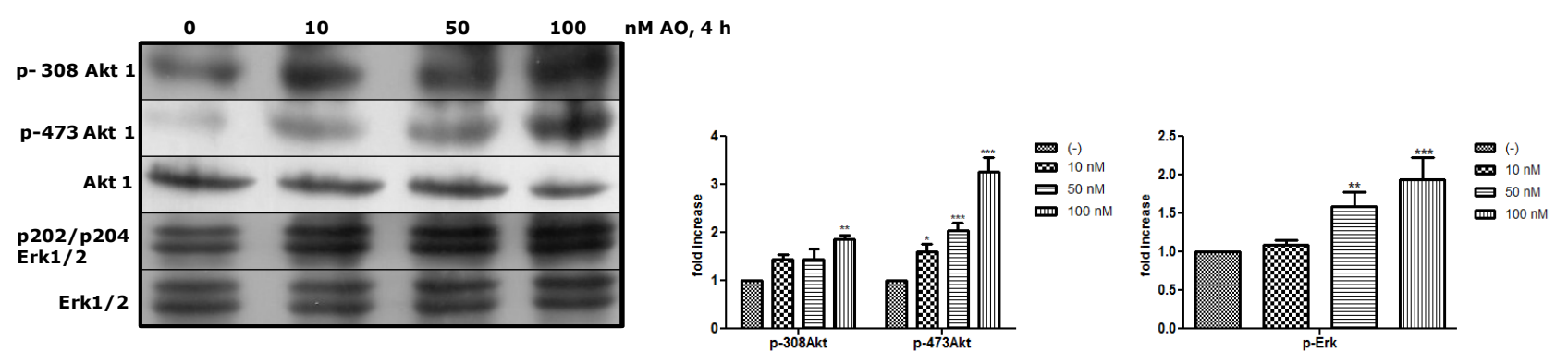

MKN-45
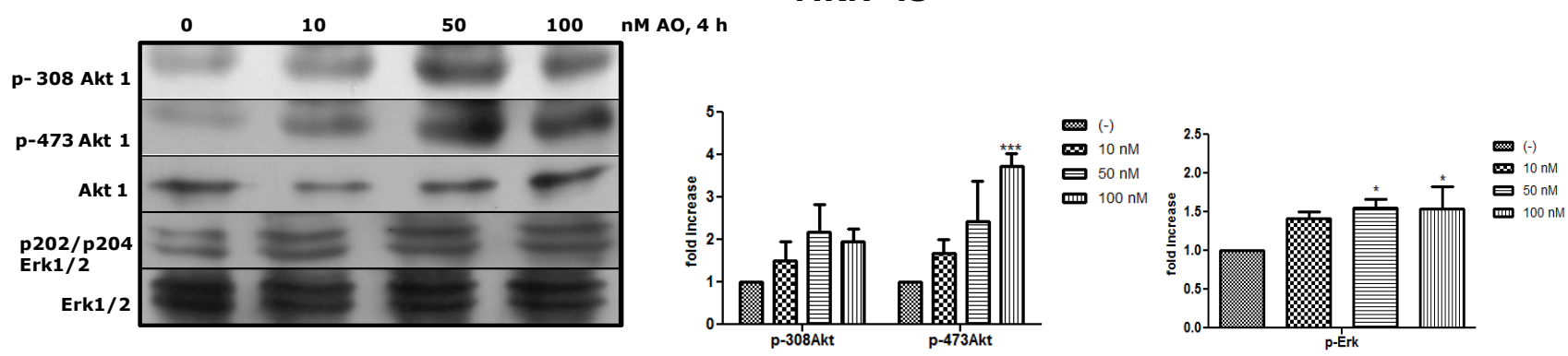

Caco 2
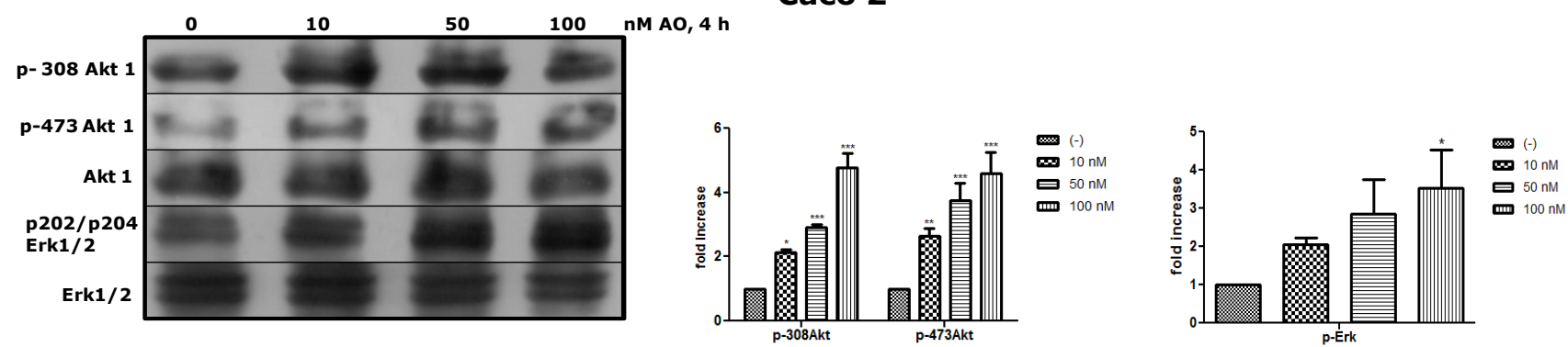


\section{Experimental Section}

\subsection{Reagents and Chemicals}

Okadaic acid (OA; NRC CRM-OA-c) was purchased from National Research Council (Halifax, Nova Scotia, Canada); Antibodies against Cyclin B1 were obtained from Santa Cruz Biotechnology (Santa Cruz, California, CA, USA); Anti Rabbit IgG Peroxidase conjugate was obtained from Thermo (Rockford, Illinois, IL, USA); Anti Mouse IgG peroxidase conjugate was obtained from Sigma (Saint Louis, Missouri, MO, USA); Erk1 + Erk2, Erk1 + Erk2 (phospho Y204/187 + T202/185), Akt-1, Akt-1 (phospho T308), Akt-1 (phospho S473) and $\beta$-Act were obtained from Abcam (Cambridge, Massachusetts, MA, USA). Bovine Serum Albumin (BSA), BCA protein assay, "AlamarBlue cell Viability assay Reagent", MTT, RIPA Buffer, Halt protease inhibitor cocktail, Phosphatase inhibitor cocktail, BupH Tris-Glycine-SDS Buffer, Surfact-Amp 20, BupH Phosphate Buffered Saline Packs, Nitrocellulose membrane $0.22 \mu \mathrm{m}$, Super Signa West Pico Chem iluminescent Substrate and Restore Western blot Stripping Buffer were obtained from Thermo (Rockford, Illinois, IL, USA).

\subsection{Cell Culture}

AGS, MKN-45 and Caco 2 (ATCC) cell lines were cultured in Dulbecco's Modified Eagle's Medium (DMEM) containing penicillin $(100 \mu \mathrm{g} / \mathrm{mL})$, streptomycin $(100 \mu \mathrm{g} / \mathrm{mL}), 1 \%$ non-essential amino acids were from Invitrogen (Grand Island, New York, NY, USA), and supplemented with $10 \%$ heat-inactivated fetal bovine serum (FBS) were from HyClone (South Logan, Utah, UT, USA). Cells were incubated in $10 \% \mathrm{CO}_{2}$ at $37{ }^{\circ} \mathrm{C}$ and harvested when they reach $70 \%-90 \%$ confluence using $0.25 \%$ trypsin/EDTA, from Invitrogen (Grand Island, New York, NY, USA).

\subsection{Cell Viability Assay}

\subsubsection{MTT Assay and AlamarBlue Assay}

Cells $\left(1 \times 10^{4}\right.$ per well $)$ were cultured in $100 \mu \mathrm{L}$ of free SFB medium for $24 \mathrm{~h}$. Then the medium was removed and replaced by fresh medium supplemented with OA at different concentrations and incubated at the indicated times. For the MTT assay, cells were incubated with 3-(4,5-dimethylthiazol-2-yl)-2,5-diphenyltetrazolium bromide (MTT), at a final concentration of $0.5 \mathrm{mg} / \mathrm{mL}$ for $2 \mathrm{~h}$. Then, $200 \mu \mathrm{L}$ of $0.1 \mathrm{~N} \mathrm{HCl}$-Isopropanol was added, and the plates were agitated for $15 \mathrm{~min}$. The AlamarBlue assay was used according to manufacturer's recommendations, $10 \%$ of reagent was incubated for $2 \mathrm{~h}$. In both assays, optical density of medium in each well was measured with an automatic microplate reader at a test wavelength of $570 \mathrm{~nm}$ and a reference wavelength of $690 \mathrm{~nm}$ for MTT assay and $600 \mathrm{~nm}$ for AlamarBlue assay.

\subsubsection{Trypan Blue Assay}

Cells $\left(1 \times 10^{5}\right)$ were cultured in $500 \mu \mathrm{L}$ free SFB medium per well for $24 \mathrm{~h}$. The medium was removed and replaced by fresh medium supplemented with OA at different concentrations and incubated at the indicated times. Cells were detached from the well using $1 \%$ trypsin/EDTA, washed 
once with PBS, and resuspended in $1 \mathrm{~mL}$ of medium. Then, cells were counted in a Neubauer chamber, 1:1 with Trypan blue.

The data are expressed considering $100 \%$ to the control condition, without OA.

\subsection{Cell Extracts}

For western blot analysis, $3 \times 10^{5}$ cells/ well were seeded in six-well plates in $2 \mathrm{~mL}$ of free SFB medium for $24 \mathrm{~h}$. Then, the medium was removed and replaced by fresh medium supplemented with $\mathrm{OA}$ at different concentrations and incubated for 4 or $24 \mathrm{~h}$. The cell extracts were prepared removing the medium from plates, washing with cold PBS, and adding RIPA buffer with protease inhibitor and phosphatase inhibitors $1 \times$. After centrifugation $\left(14,000 \times g\right.$ for $15 \mathrm{~min}$ at $\left.4{ }^{\circ} \mathrm{C}\right)$, the protein concentration was determined with BCA protein assay at $\lambda=595 \mathrm{~nm}$ with BSA as standard. Then, the samples were heated for $5 \mathrm{~min}$ at $100^{\circ} \mathrm{C}$ in the presence of SDS and $\beta$-mercaptoethanol.

\subsection{Western Blotting}

Ten micrograms of proteins from total cells were subjected to SDS-PAGE on $15 \%$ SDS-polyacrylamide gel electrophoresis and transferred onto nitrocellulose membrane. The membranes were blocked with PBS-buffered saline containing 0.1\% Tween-20 (PBST) and 1\% BSA for $60 \mathrm{~min}$ at room temperature and probed with antibodies against Cyclin B1 $(1: 2,500)$, Akt-1 (1:5000), Akt-1 (phospho T308) (1:5000), Akt-1 (phosphor S473) (1:5000), Erk1 + Erk2 (1:5000), Erk1 + Erk2 (phospho Y204/187 + T202/185) (1:5000) and $\beta$-actin (1:7500) overnight at $4{ }^{\circ} \mathrm{C}$ and washed three times with PBST. The membranes were probed with horseradish peroxidase-conjugated secondary antibodies at 1:5000 for $1 \mathrm{~h}$ at room temperature and washed with PBST three times. The immunoblots were visualized by enhanced chemiluminescence. Densitometrical measurement of the band of interest was done using the GelPro 31 software (Media Cybernetics Inc., Silver Spring, MD, USA). Normalization was done using $\beta$-actin, Akt-1 or Erk1 + Erk2 values.

\subsection{Statistical Analyses}

The results of the experiments were expressed as the mean $\pm \mathrm{SE}$. Comparisons between the groups were made using a two-way ANOVAs and the Bonferroni post-test. The statistical significance was defined as a $P$ value smaller than 0.05 . The analyses were performed using GraphPad Prism software (La Jolla, California, CA, USA).

\section{Conclusions}

Our results demonstrate that sublethal concentrations of OA can promote the cellular mitotic rate, overexpression of Cyclin B and activation of cell proliferation pathways such as Akt and Erk. In the consumption of shellfish contaminated with diarrheal toxins, the bioavailability of these molecules is very different from the experimental model used. Nevertheless, we believe that our work is a contribution to the elucidation of why these toxins are considered to be tumor promoters. 


\section{Acknowledgments}

We would like to thank Carlos García and Cristobal Contreras, for all their support and help in the development of this work, María Inés Becker and "Science and Technology for the developed" Foundation for their generous assistance in providing the facilities of the Foundation and giving us the Caco 2 cell line, and Alejandro Corvalán, of the Pathology and Molecular Epidemiology Laboratory, PUC, for his support and for providing us the AGS and MKN-45 cells lines. The project was funded by Fondecyt 1130037 (M.d.C.; N.L.) and Fondecyt 1120126 (H.T.).

\section{Conflicts of Interest}

The authors declare no conflict of interest.

\section{References}

1. Alexander, J.; Audunsson, G.A.; Benford, D.; Cockburn, A.; Cradevi, J.P.; Dogliotti, E.; Domenico, A.D.; Fernandez-Cruz, M.L.; Fink-Gremmels, J.; Furst, P.; et al. Marine biotoxins in shellfish — okadaic acid and analogues-Scientific Opinion of the Panel on Contaminants in the Food chain. EFSA J. 2008, 589, 1-62.

2. Aune, T.; Stabell, O.B.; Nordstoga, K.; Tjotta, K. Oral toxicity in mice of algal toxins from the diarrheic shellfish toxin (DST) complex and associated toxins. J. Nat. Toxins 1998, 7, 141-158.

3. Tripuraneni, J.; Koutsouris, A.; Pestic, L.; De Lanerolle, P.; Hecht, G. The toxin of diarrheic shellfish poisoning, okadaic acid, increases intestinal epithelial paracellular permeability. Gastroenterology 1997, 112, 100-108.

4. Fujiki, H.; Suganuma, M. Carcinogenic aspects of protein phosphatase 1 and 2A inhibitors. Prog. Mol. Subcell Biol. 2009, 46, 221-254.

5. Manerio, E.; Rodas, V.L.; Costas, E.; Hernandez, J.M. Shellfish consumption: A major risk factor for colorectal cancer. Med. Hypotheses 2008, 70, 409-412.

6. Bialojan, C.; Takai, A. Inhibitory effect of a marine-sponge toxin, okadaic acid, on protein phosphatases. Biochem. J. 1988, 256, 283-290.

7. Westermarck, J.; Hahn, W.C. Multiple pathways regulated by the tumor suppressor PP2A in transformation. Trends Mol. Med. 2008, 14, 152-160.

8. Fujiki, H.; Suganuma, M. Tumor promoters - microcystin-LR, nodularin and TNF- $\alpha$ and human cancer development. Anticancer Agents Med. Chem. 2011, 11, 4-18.

9. Baharians, Z.; Schonthal, A. Reduction of Ha-ras-induced cellular transformation by elevated expression of protein phosphatase type 2A. Mol. Carcinog. 1999, 24, 246-254.

10. Guénin, S.; Schwartz, L.; Morvan, D.; Steyaert, J.M.; Poignet, A.; Madelmont, J.C.; Demidem, A. PP2A activity is controlled by methylation and regulates oncoprotein expression in melanoma cells: A mechanism which participates in growth inhibition induced by chloroethylnitrosourea treatment. Int. J. Oncol. 2008, 32, 49-57.

11. Matias, W.G.; Traore, A.; Creppy, E.E. Variations in the distribution of okadaic acid in organs and biological fluids of mice related to diarrhoeic syndrome. Hum. Exp. Toxicol. 1999, 18, $345-350$. 
12. Aune, T.; Espenes, A.; Aasen, J.A.; Quilliam, M.A.; Hess, P.; Larsen, S. Study of possible combined toxic effects of azaspiracid-1 and okadaic acid in mice via the oral route. Toxicon 2012, 60, 895-906.

13. Ito, E.; Yasumoto, T.; Takai, A.; Imanishi, S.; Harada, K. Investigation of the distribution and excretion of okadaic acid in mice using immunostaining method. Toxicon 2002, 40, 159-165.

14. Fessard, V.; Grosse, Y.; Pfohl-Leszkowicz, A.; Puiseux-Dao, S. Okadaic acid treatment induces DNA adduct formation in BHK21 C13 fibroblasts and HESV keratinocytes. Mutat. Res. 1996, 36, 133-141.

15. Jayaraj, R.; Gupta, N.; Rao, P.V. Multiple signal transduction pathways in okadaic acid induced apoptosis in HeLa cells. Toxicology 2009, 256, 118-127.

16. Kitazumi, I.; Maseki, Y.; Nomura, Y.; Shimanuki, A.; Sugita, Y.; Tsukahara, M. Okadaic acid induces DNA fragmentation via caspase-3-dependent and caspase-3-independent pathways in Chinese hamster ovary (CHO)-K1 cells. FEBS J. 2010, 277, 404-412.

17. Ravindran, J.; Gupta, N.; Agrawal, M.; Bala Bhaskar, A.S.; Lakshmana Rao, P.V. Modulation of ROS/MAPK signaling pathways by okadaic acid leads to cell death via, mitochondrial mediated caspase-dependent mechanism. Apoptosis 2011, 16, 145-161.

18. Fisher, D.; Krasinska, L.; Coudreuse, D.; Novák, B. Phosphorylation network dynamics in the control of cell cycle transitions. J. Cell Sci. 2012, 125, 4703-4711.

19. Rodgers, J.T.; Vogel, R.O.; Puigserver, P. Clk2 and B56 $\beta$ mediate insulin-regulated assembly of the PP2A phosphatase holoenzyme complex on Akt. Mol. Cell 2011, 41, 471-479.

20. Letourneux, C.; Rocher, G.; Porteu, F. B56-containing PP2A dephosphorylate ERK and their activity is controlled by the early gene IEX-1 and ERK. EMBO J. 2006, 25, 727-738.

21. Souid-Mensi, G.; Moukha, S.; Mobio, T.A.; Maaroufi, K.; Creppy, E.E. The cytotoxicity and genotoxicity of okadaic acid are cell-line dependent. Toxicon 2008, 51, 1338-1344.

22. Parkman, H.P.; Jones, M.P. Tests of gastric neuromuscular function. Gastroenterology 2009, 136, $1526-1543$.

(C) 2013 by the authors; licensee MDPI, Basel, Switzerland. This article is an open access article distributed under the terms and conditions of the Creative Commons Attribution license (http://creativecommons.org/licenses/by/3.0/). 